TERRA. Revista de Desarrollo Local e-ISSN: 2386-9968

Número 6 (2020), 350-357

DOI 10.7203/terra.6.16821

IIDL - Instituto Interuniversitario de Desarrollo Local

\title{
Reseña. Informe sobre la evolución y la situación territorial de la Comunitat Valenciana
}

\section{Francisco Javier Soriano Martí}

Dep. D’Història, Geografia i Art. Geografia Humana (CEFIRE Castelló i Universitat Jaume I, Castelló, Espanya)

fsoriano@uji.es

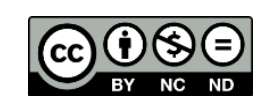

Esta obra se distribuye con la licencia Creative Commons Reconocimiento-NoComercial-SinObraDerivada 4.0 Internacional 


\section{SECCIÓN RESEÑAS}

\section{Reseña. Informe sobre la evolución y la situación territorial de la Comunitat Valenciana}

Resumen. Esta publicación aporta una completa visión de la situación actual de la Comunitat Valenciana desde el punto de vista socioeconómico, ambiental y, como concepto integrador, desde una perspectiva territorial. Podría decirse, aunque sin duda no era su objetivo, que es como una versión actualizada y mejorada de un manual clásico de geografía regional de la Comunitat Valenciana/País Valencià, aunque faltarían algunos capítulos esenciales (tradicionales) en lo referente al medio físico. El libro permite aprender y reflexionar sobre muchos aspectos de actualidad (despoblamiento, movilidad sostenible, urbanización, inteligencia territorial, infraestructura verde, custodia del territorio, Objetivos de Desarrollo Sostenible, etc.), por lo que resulta del máximo interés para el gran público a pesar de su extensión. Obra de diversos especialistas y, por tanto, interdisciplinar, llama la atención que uno de sus nueve capítulos esté en valencià.

Palabras clave: despoblamiento, movilidad sostenible, urbanización, inteligencia territorial, infraestructura verde.

Recibido: 12 de marzo de 2020

Devuelto para revisión: -

Aceptado: 12 de marzo de 2020

Referencia / Citation:

Soriano, F. J. (2020). Reseña. Informe sobre la evolución y la situación territorial de la Comunitat Valenciana. TERRA. Revista de Desarrollo Local, (6), 350-357. DOI 10.7203/terra.6.16821 
Joaquín Farinós (coord.). Joaquín Farinós y Enrique Peiro (eds.)

\section{INFORME SOBRE LA EVOLUCIÓN Y LA SITUACIÓN TERRITORIAL DE LA COMUNITAT VALENCIANA}

Publicacions de la Universitat de València (PUV), 2019. 502 páginas.

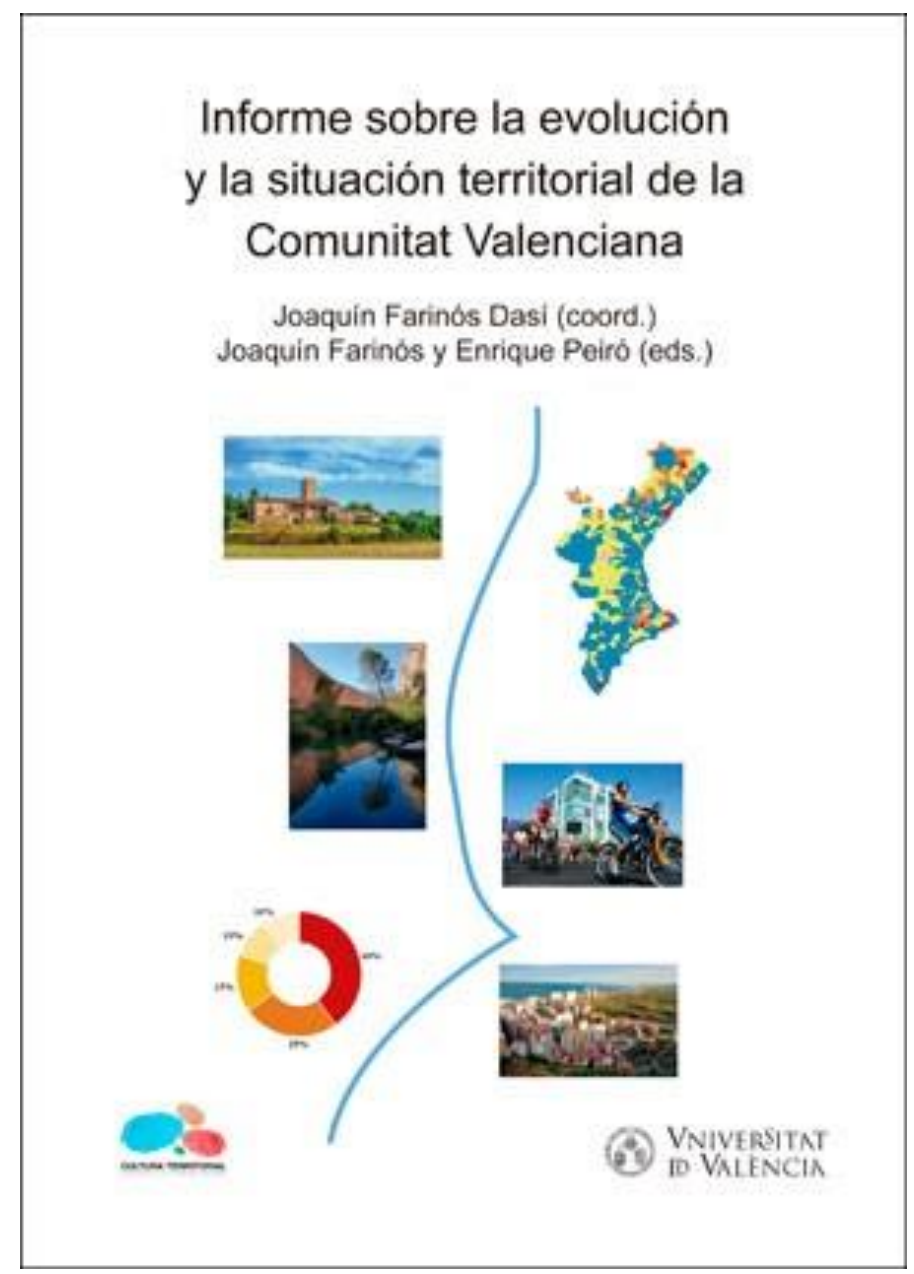

Esta publicación aporta una completa visión de la situación actual de la Comunitat Valenciana desde el punto de vista socioeconómico, ambiental $\mathrm{y}$, como concepto integrador, desde una perspectiva territorial. Podría decirse, aunque sin duda no era su objetivo, que es como una versión actualizada y mejorada de un manual clásico de geografía regional de la Comunitat Valenciana/País Valencià, aunque faltarían algunos capítulos esenciales (tradicionales) en lo referente al medio físico.

El libro permite aprender y reflexionar sobre muchos aspectos de actualidad (despoblamiento, movilidad sostenible, urbanización, inteligencia territorial, infraestructura verde, custodia del territorio, Objetivos de Desarrollo Sostenible, etc.), por lo que resulta del máximo interés para el gran público a pesar de su extensión. Obra de diversos especialistas y, por tanto, interdisciplinar, llama la atención que uno de sus nueve capítulos esté en valencià.

El título es, probable y paradójicamente, uno de los puntos débiles porque suele resultar poco atractivo leer un 'Informe' y, en cambio, aparentemente la obra pretende ser de divulgación, aunque también académica y dirigida a un público experto. Quizás se hubiera podido apostar por algo más sugerente para atraer a un lector más generalista. Todos los capítulos invierten un generoso espacio en realizar cuadros de síntesis con las principales ideas de cada apartado, lo cual facilita la lectura abreviada de la obra, por decirlo de alguna manera. En contraste, los sumarios o índices de los capítulos no son de mucha ayuda porque se ha huido del típico formato en vertical para colocar los puntos o apartados a texto corrido, con lo que son muy poco visuales.

Los objetivos de la obra, en cualquier caso, se cumplen y puede afirmarse que a pesar de la complejidad de algunos temas tratados, la lectura es ágil y hasta incluso amena por la gran profusión de elementos gráficos y cartográficos. Por desgracia, son frecuentes los 
problemas de lectura de los mapas, la infografía y los gráficos, bien sea por la tipografía empleada bien por el tamaño o formato de la publicación.

Tampoco se ha homogeneizado la nomenclatura, algo sumamente complejo y que a menudo tiene que ver con ideologías y convicciones personales. El continuo debate entre Comunitat Valenciana o País Valencià se eterniza. El título del libro no permite dudar porque apuesta por la denominación oficial, pero muchos autores utilizan en sus capítulos el otro término, lo cual contribuye a la indeterminación. Algo similar ocurre con las citas bibliográficas, que no son uniformes en toda la obra, aspecto que desde el punto de vista formal resulta necesariamente mejorable.

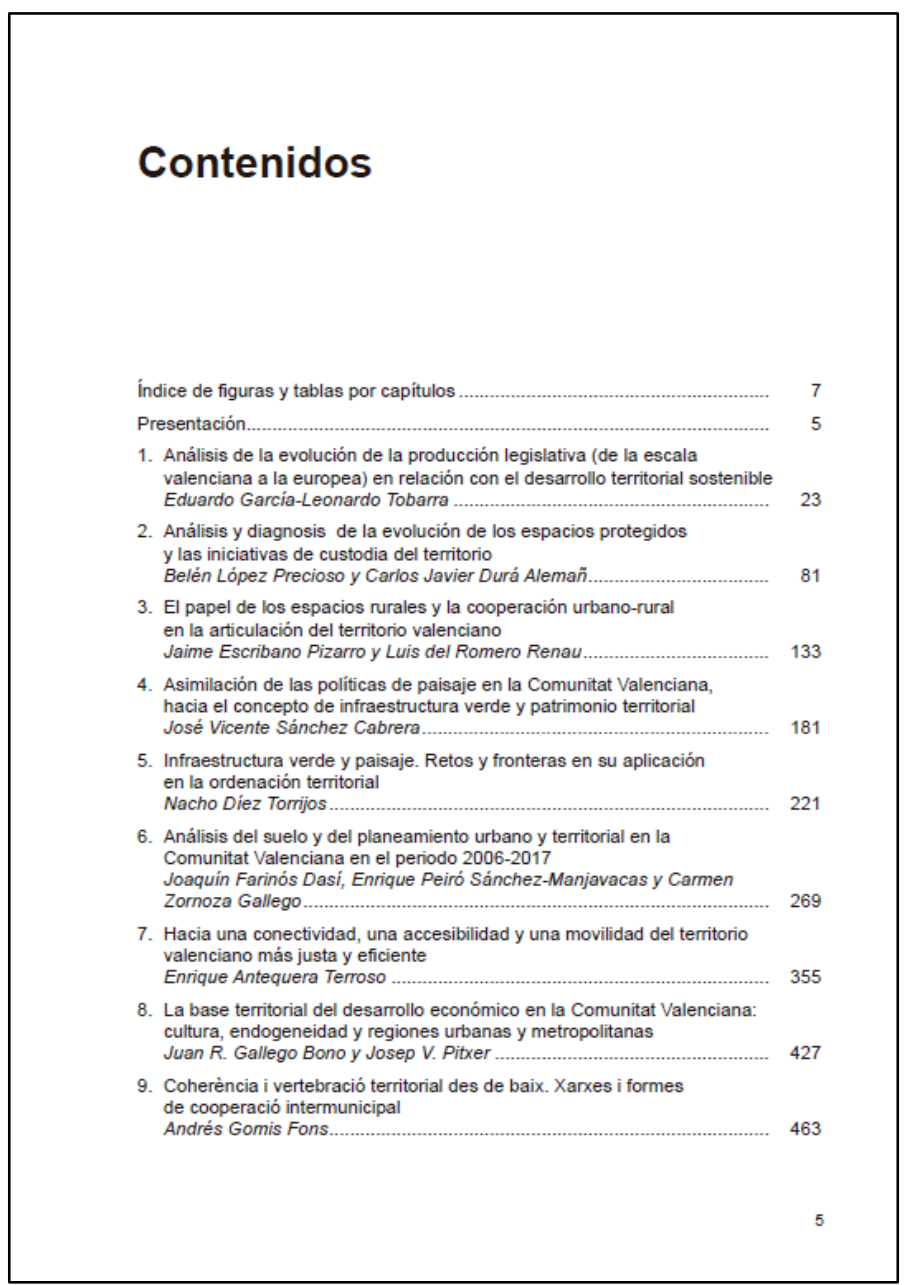

El capítulo 1, destinado a analizar la producción legislativa en relación al desarrollo territorial sostenible, firmado por Eduardo García-Leonardo (pp. 23-80), se muestra crítico y denuncia los múltiples errores cometidos por la Administración ("la Generalitat, en un claro ejemplo de irresponsabilidad en el ejercicio de sus competencias, deshizo el escaso planeamiento comarcal existente, devolviendo a los municipios la competencia para la redacción y tramitación de su planeamiento urbanístico", p 46), además de tildar de 'torpeza' las sucesivas modificaciones legales (LOTPP, LOTUP...). El crecimiento de la superficie urbanizada o artificial, con 713.214 nuevas viviendas en la década 1997-2006, es analizado con todo detalle para concluir que "la LRAU trata de facilitar al máximo la gestión urbanística, lo que, en la práctica,

facilitó los procesos de urbanización descontrolada" (p. 52). Demasiadas muestras conocemos todos.

El siguiente capítulo estudia la situación de los ENP (Espacios Naturales Protegidos) y las iniciativas de custodia del territorio. Es obra de Belén López y Carlos Javier Durá (pp. 81-131), que aportan una visión descriptiva con información útil (mapas, listados, etc.), actualizada y crítica, porque es una evidencia que la Generalitat Valenciana todavía no ha sido capaz de impulsar la redacción de los PRUG de algunos de sus parques naturales (Serra Gelada, Penyagolosa, Chera-Sot de Chera...), con lo que la Administración autonómica continúa incumpliendo sus propias leyes para escarnio público. La custodia del territorio (iniciativas de conservación y gestión de valores naturales, culturales y paisajísticos lideradas por agentes o asociaciones de la sociedad civil) se resumen en unas pocas páginas finales para poner en valor esa labor. Alguna errata incomprensible, como 
ubicar la finca del Barranc dels Horts (Fundació Bancaixa) en la Sierra de Espadán (p. 125) no le resta importancia a ese apartado.

El capítulo 3 se centra en analizar una cuestión que ha cobrado actualidad tras acuñarse el concepto de la España vacía (igracias Sergio del Molino!), aunque en realidad retoma aquella idea de los años 80 del siglo XX del umbral desvitalizado de la España interior. Firmado por Jaime Escribano y Luis del Romero (pp. 133-180), presenta una cartografía muy rica y que permite descubrir o redescubrir el grave problema del despoblamiento. Los autores son críticos ante la escasa efectividad de la ordenación del territorio rural hasta la fecha, a pesar de los anuncios políticos (¿se quedarán en eso como suele ocurrir siempre?) del plan AVANT y la Agenda Valenciana Antidespoblación, que afectará a 214 municipios.

El análisis resulta demoledor y nos descubre que el despoblamiento se extiende actualmente incluso hacia zonas periurbanas. Escribano y Del Romero se atreven a hablar de una nueva geografía del medio rural valenciano y cuestionan la fórmula de un medio rural como parque temático (centro de eventos, ferias, festividades, pruebas deportivas, etc.) como mecanismo para atraer nueva población o diversificar la economía.

La Estrategia Territorial de la Comunitat Valenciana y los Planes de Acción Territorial, desarrollados ya en pleno siglo XXI, se plantean mejorar las condiciones de vida del medio rural, contener la dispersión urbana y fomentar la actividad rural aplicando el principio de discriminación positiva, pero la Administración no ha desarrollado figuras contempladas en la legislación y la que sí está en activo, el PATFOR o Plan de Acción Territorial Forestal, "no parece haber tenido una incidencia palpable sobre el medio rural, ni siquiera sobre el sector forestal" (p. 144).

Algo similar ocurre con los Programas de Desarrollo Rural, en concreto con la medida 421 del Eje 4, especialmente destinada a promover la cooperación interterritorial. Como se afirma, "se trata de una medida non nata" (p. 153). ¿Qué hacer por lo tanto? Se supone que seguir denunciando y apelando a la responsabilidad de políticos y técnicos, aunque la puesta en marcha de la Agenda Valenciana Antidespoblament (AVANT) en 2017 vuelve a provocar frustración. Se plantea hacer un diagnóstico del problema -como si no hubiera suficientes realizados- y las intenciones son buenas, pero "el presupuesto total dedicado es de apenas 3 millones de euros para todos los municipios, con lo que la capacidad de llevar a cabo proyectos ambiciosos es bastante limitada" (p. 160). En definitiva, el futuro no es en absoluto prometedor y la prevalencia de una visión 'urbanocéntrica' parece condenar a nuestro medio rural a un abandono progresivo, latente, silencioso...

El capítulo 4 se centra en el estudio del paisaje y está escrito por el geógrafo y profesor José Vicente Sánchez (pp. 181-219). La síntesis de los tratados europeos que versan sobre el paisaje y su estudio es exhaustivo, así como el análisis legislativo. Aparecen hasta desideratas o nuevos incumplimientos de los objetivos fijados por la legislación o la Administración, como por ejemplo la inexistencia de un Observatorio del Paisaje de la Comunitat Valenciana. Comparar la función del Observatori del Paisatge catalán o la red de museos del Museu Nacional de la Tècnica i la Ciència de Catalunya con la realidad valenciana es decepcionante ante la falta de iniciativas de ese tipo al sur del río Sénia, a pesar de nuestro enorme potencial paisajístico, patrimonial, natural e histórico.

Y sí, es cierto, "el paisaje se percibe como uno de los pocos elementos que todavía es capaz de combatir los efectos y consecuencias que está teniendo la globalización en el territorio. Refuta las formas y maneras más banales, los procesos estandarizados o replicados en masa" (p. 182). En cambio, en la Comunitat Valenciana, se hacen pocos 
esfuerzos para ponerlo en valor. $\mathrm{O}$ aquellos que se han hecho, resultan inadecuados, como la efímera señalización de la carretera Onda-Montanejos como 'carretera paisajística'.

La formulación de la Nueva Política del Paisaje de la Comunitat Valenciana entre 2004 y 2012 se ha visto acompañada por el Reglamento de Paisaje y la Ley 16/2005 Urbanística Valenciana (LUV), que instaura los Estudios de paisaje y los Estudios de integración paisajística, así como por la Ley 5/2014 de Ordenación del Territorio, Urbanismo y Paisaje (LOTUP), que elimina la técnica del metro por metro e introduce variables de análisis objetivo como el Valor paisajístico, Fragilidad paisajística y Fragilidad visual de las unidades de paisaje.

No obstante, la gran aportación en este ámbito, incluyendo el relativamente nuevo concepto de infraestructura verde (corredores ecológicos), ha sido el PATIVEL (Plan de Acción Territorial de la Infraestructura Verde Litoral de la Comunitat Valenciana) que se centra en los frentes costeros de Vinaròs-Benicarló, la Albufera, Gandia y el litoral entre Alicante-Elche.

El concepto de paisaje y su relación con la infraestructura verde centra la atención del capítulo 5 (pp. 221-267), obra de Nacho Díez, doctor ingeniero agrónomo. Tras realizar un completo repaso del concepto 'paisaje', citar a todos los expertos (Mata, Tarroja, Martínez, Nogué, Mateu...) y concretar aspectos como la dualidad paisaje-territorio vs paisaje-imagen, la medianza humana (retroalimentación permanente entre entorno y sociedad) o la 'urbanalización' definida por Francesc Muñoz (surgen espacios de baja calidad, descontextualizados... en realidad no lugares como aeropuertos, centros comerciales, parques temáticos, etc.), se centra en analizar la nueva cultura del territorio con la gobernanza y la gestión participativa como herramientas clave.

La siguiente entrega del 'Informe' versa sobre el planeamiento urbano y las tipologías del suelo (urbanizable, urbano, industrial...). Firmado por los dos editores, Joaquín Farinós y Enrique Peiró, en compañía de Carmen Zornoza, destaca por la profusión y claridad de sus contenidos cartográficos a lo largo de 84 páginas (pp. 269 a 353). El capítulo puede pecar de un exceso descriptivo, aunque el análisis retrospectivo referente a la ordenación del territorio y las leyes urbanísticas lo exigía hasta cierto punto y sirve, como en apartados precedentes, para confirmar con tristeza la falta de aplicación de planes aprobados y contemplados en la legislación, como el PAT del Litoral o, en su conjunto, la política de ordenación del territorio.

El texto remarca las nuevas tendencias de gestión territorial, conducente a promover servicios y desarrollo ecosistémico, es decir, se busca la obtención de beneficios ambientales y socioeconómicos de forma conjunta o integral para garantizar la conservación y el progreso. Por otra parte, la máxima actualización del informe permite a sus autores destacar que la revisión en 2019 de la LOTUP va a permitir, por lo menos en teoría, la recuperación de la función social del urbanismo, relegando la exagerada especulación de las últimas décadas.

El 'pero' del texto gira en torno a la cuestión toponímica. ¿Cómo es posible que se utilice un topónimo no oficial y aparentemente desterrado como Villareal (Vila-real es el único correcto aunque el equipo de fútbol de Primera división sea el Villarreal CF)? Lo mismo ocurre con Useras (les Useres), Benasal (Benassal) o San Jorge (Sant Jordi), pero en cambio se utiliza Benicàssim. Un galimatías toponímico propio de tierras bilingües, pero que debería ser resuelto con mimo en una publicación de estas características.

El capítulo 7 analiza el sistema de transporte de la Comunitat Valenciana desde una perspectiva innovadora, ya que ahora es concebido como servicio capaz de garantizar la 
equidad territorial y la eficiencia. Obra de Enrique Antequera (pp. 355-425), cuya filiación es el departamento de Urbanismo de la UPV, coincide con el apartado anterior por la calidad de su cartografía y el esfuerzo de ofrecer una visión analítica plenamente actualizada del sector. Se repasan conceptos clave (conectividad, accesibilidad, movilidad sostenible e inteligente...) desde una perspectiva crítica (infraestructuras ejecutadas difíciles de justificar por su escasa rentabilidad) y se destaca la inelasticidad inversión en infraestructuras-crecimiento económico en territorios bien dotados.

Las estadísticas de transporte sirven para evidenciar la enorme dependencia del vehículo privado a todas las escalas (europea, española, valenciana), lo cual hace más incomprensible todavía que el transporte no se integre expresamente en los ODS. Por otra parte, el completo análisis estadístico-territorial (más de 12 millones de desplazamientos diarios en la Comunitat Valenciana a razón de 2,43 por habitante y día) que plantea el autor permite situar a la red viaria autonómica en su justo lugar mediante la utilización de variables de cierta complejidad como el índice de dotación viaria respecto a los habitantes o la superficie de carreteras por cada $1.000 \mathrm{~km}^{2}$, si bien no es menos cierto que los resultados finales no son sorprendentes: "en la Comunitat puede existir un déficit, no tanto en la red de altas prestaciones, como en la de segundo orden, cuya función principal sería la de mallar el territorio" (p. 377), algo que mejoraría la conectividad general.

La referencia a la clásica teoría de los lugares centrales permite al autor reforzar argumentos tradicionales que, sin embargo, son obviados en investigaciones que, a menudo, olvidan la esencia territorial, porque efectivamente "con demasiada frecuencia se minusvalora la importancia de la localización que, en última instancia, es la que marca un umbral mínimo de accesibilidad de cualquier punto de un territorio" (p. 389). Con este escenario, no extraña la denuncia referida a los municipios del extremo NW de la provincia de Castelló, con accesibilidades impropias del siglo XXI y hasta más de 80 minutos de viaje para alcanzar la capital de La Plana.

Las conclusiones, en cualquier caso, acaban resultando evidentes, conocidas y fraguadas a lo largo de la historia... y no solo desde la llegada de la motorización: "Esa dicotomía entre un litoral densamente poblado y un interior despoblado, tienen una traducción negativa a efectos de accesibilidad, sobre la que no resulta sencillo actuar" (p. 418).

El único 'pero' del capítulo son algunas erratas ortotipográficas fácilmente subsanables pero que desvelan la falta de una edición más cuidada, con correctores expertos. En la página 400 hasta se repite el inicio de la frase "Descendiendo a la desagregación por modos" en dos ocasiones. Una lástima.

El capítulo 8, firmado por Juan R. Gallego y Josep V. Pitxer, focaliza la atención en la economía de zonas urbanas y metropolitanas. Pese a un inicio muy teórico, posteriormente se adentra en el análisis de la economía regional valenciana desde una perspectiva interesante y actual (geografía económica evolucionista, economías de alcance, redefinición de los 'clusters' o tradicionales distritos industriales...), con importante apoyo cartográfico y estadístico, pero con resultados más o menos esperables. Y no es un comentario crítico, es la constatación de la realidad económica.

L'obra finalitza amb un capítol escrit per Andrés Gomis que aporta un plantejament molt innovador, ja que sota el títol "Coherència i vertebració territorial des de baix. Xarxes i formes de cooperació intermunicipal" (pp. 463-502) realitza un complet estudi de les mancomunitats existents a la Comunitat i analitza la seua funció i efectivitat en la gestió territorial. Aquesta idea no és nova, però és cert que ha rebut un important i decidit impuls des de la Unió Europea. De fet, a partir de la publicació del Llibre verd de la cohesió territorial, la UE defensa el foment d'un desenvolupament policèntric amb l'objectiu 
d'evitar la concentració de l'activitat econòmica i la població. I clar, com l'autor argumenta, "la cooperació pot ser una eina per a afavorir l'equitat territorial i el desenvolupament policèntric" ( $p$. 465), encara que fa falta la col-laboració entre Administració, empreses i actors privats (la societat).

El problema, conegut des de fa anys, és que una de les formes de cooperació institucional més fortes -o potencialment més forta- mai s'ha desenvolupat per diferents raons. Si a Catalunya sí existeix una conciència comarcal important, a la Comunitat Valenciana mai ha fructificat, excepte casos aïllats. Com diu l'autor, les comarques, "tot i que estan referenciades en l'Estatut d'Autonomia i en la Llei de règim local de la Comunitat Valenciana, mai han sigut creades com a entitats locals territorials" (p. 473).

La cooperació intermunicipal, no obstant això, està present amb 56 mancomunitats que actuen en un $72 \%$ del territori o els 40 consorcis (54\% del territori), com permet comprovar l'anàlisi realitzat al capítol. I la conclusió és clara, les mancomunitats són fonamentals per a la dinamització dels territoris que més alt risc tenen de despoblament.

Francisco Javier Soriano Martí

Dep. D’Història, Geografia i Art. Geografia Humana

Universitat Jaime I de Castelló 